\title{
Níveis de proteína bruta em dietas para alevinos de acará-bandeira
}

\section{Jener Alexandre Sampaio Zuanon ${ }^{1}$, Ana Lúcia Salaro1, Eric Márcio Balbino², Alysson Saraiva ${ }^{2}$, Moisés Quadros ${ }^{3}$, Rodrigo Lima Fontanari ${ }^{4}$}

\author{
${ }^{1}$ Departamento de Biologia Animal da Universidade Federal de Viçosa, Av. P. H. Rolfs s/n, Viçosa MG, CEP: $36.570-000$. \\ 2 Curso de Zootecnia da UFV. \\ 3 Programa de Pós-Graduação em Zootecnia - UFV. \\ 4 Engenheiro-Agrônomo - UFV.
}

RESUMO - Neste estudo, avaliaram-se as exigências nutricionais de proteína para alevinos de acará-bandeira. O delineamento experimental utilizado foi o inteiramente casualizado, com quatro tratamentos $(34,38,42$ e $46 \%$ de PB) e quatro repetições. Alevinos $(0,44 \pm 0,05 \mathrm{~g})$ foram distribuídos em 16 aquários com volume individual de $25 \mathrm{~L}$, dotados de sistema de filtragem, aeração e controle de temperatura $\left(26 \pm 0,5^{\circ} \mathrm{C}\right)$, em densidade de estocagem de seis peixes/aquário, onde foram alimentados à vontade, às $8,11,14$ e $17 \mathrm{~h}$, durante 60 dias. Os parâmetros de desempenho produtivo avaliados foram: peso final, ganho de peso, consumo de ração, conversão alimentar, taxa de crescimento específico e taxa de eficiência protéica (TEP). Ao final do experimento, não foi observado efeito significativo dos tratamentos sobre o desempenho produtivo, exceto para a TEP. A dieta com $46 \%$ de PB resultou em TEP significativamente menor que as dietas com 34 e $38 \%$ PB, enquanto a dieta com $42 \%$ de PB não diferiu das demais. Dietas contendo $34 \%$ de PB atendem às exigências nutricionais em proteína de alevinos de acará-bandeira.

Palavras-chave: crescimento, desempenho produtivo, exigências nutricionais, peix es ornamentais, Pterophyllum scalare

\section{Dietary crude protein levels of freshwater angelfish fry}

\begin{abstract}
The aim of this experiment was to evaluate dietary protein requirements of freshwater angelfish fry. A complete randomized design with four dietary crude protein levels $(34,38,42$, and $46 \%$ of CP) and four replicates was used. Fish averaging $0.44 \pm 0.05 \mathrm{~g}$ were reared in sixteen $25 \mathrm{~L}$-aquarium with aeration, biological filter and controlled temperature $\left(26 \pm 0.5^{\circ} \mathrm{C}\right)$, in a stocking density of six fish/aquarium. Fish were fed ad libitum at 8:00 a.m., 11:00 a.m., 2:00 p.m, and 5:00 p.m, during 60 days. Final weight, weight gain, feed intake, feed:gain ratio, specific growth rate and protein efficiency rat io (PER) were the evaluated parameters of productive performance. At the end of the experiment, no treatment effect on productive performance, with the exception of PER was observed. Fishes fed diets with $46 \%$ CP showed PER significant smaller than those fed diets with 34 and $38 \%$ of CP. PER of fish fed diets with $42 \%$ of CP did not differ from the other treatments. Diets with $34 \%$ of $\mathrm{CP}$ can meet the protein nutritional requirements of freshwater angelfish fry.
\end{abstract}

Key Words: growth, nutritional requirements, ornamental fish, productive performance, Pterophyllum scalare

\section{Introdução}

O comércio de peixes ornamentais é considerado um dos setores mais lucrativos da piscicultura brasileira e vem se expandindo rapidamente com o aumento na demanda mundial (Lima et al., 2001).

O estado de Minas Gerais destaca-se como um dos maiores centros de produção do Brasil, com 118 criadores que cultivam 50 variedades e/ou espécies (Pezzato \& Scorvo Filho, 2000). A região do município de Muriaé, na Zona da Mata Mineira, destaca-se como o principal pólo de criação, com grande número de produtores dedicando-se à criação do acará-bandeira (Pterophyllum scalare). Essa espécie destaca-se pela beleza, docilidade e convivência pacífica com inúmeras outras espécies, estando entre as oito espécies de peixes ornamentais mais importadas pelos Estados Unidos (Chapman et al., 1997).

A expansão do setor produtivo de peixes ornamentais e o conseqüente suprimento dos mercados interno e externo dependem da intensificação dos sistemas de produção e da geração de tecnologias adequadas. Por isso, é necessário o conhecimento das exigências nutricionais de cada espécie para a formulação de rações balanceadas. Em revisão apresentada por Sales \& Janssens (2003) sobre exigências nutricionais de peixes ornamentais, constata-se que são escassas as informações até mesmo 
sobre exigências de proteína e energia para a maioria das espécies.

Quando se procura determinar as exigências nutricionais de uma espécie animal, o primeiro passo deve ser a estimativa da exigência em proteína, principal componente para o crescimento e o mais oneroso nutriente da dieta. O fornecimento de dietas com conteúdo protéico insuficiente resulta na redução do crescimento, enquanto o excesso é parcialmente utilizado para síntese de proteínas e o restante é convertido em energia (Wilson \& Halver, 1986).

Dessa forma, a disponibilidade de informações sobre o nível ótimo de proteína na dieta é importante para o crescimento rápido dos peixes, a eficiência de utilização de nutrientes e a redução dos custos de alimentação.

O objetivo neste experimento foi avaliar as exigências protéicas de alevinos de acará-bandeira (Pterophyllumscalare).

\section{Material e Métodos}

O experimento foi realizado no Laboratório de Nutrição de Peixes do Setor de Piscicultura do Departamento de Biologia Animal da Universidade Federal de Viçosa, ViçosaMG, em delineamento experimental inteiramente casualizado, constituído de quatro tratamentos e quatro repetições. Os tratamentos consistiram de dietas isocalóricas $(3.200 \mathrm{kcal}$ de $\mathrm{ED} / \mathrm{kg}$ de ração) contendo níveis crescentes de $\mathrm{PB}$ (34, 38,42 e $46 \%$ ).

As rações (Tabelas $1 \mathrm{e} 2$ ) foram formuladas para atender às exigências de energia e de aminoácidos essenciais de tilápias-do-nilo, de acordo com o NRC (1993), com base na composição química dos alimentos descrita por Rostagno et al. (2000). A proteína e energia digestíveis foram calculadas com base nos coeficientes de digestibilidade para tilápia-do-nilo, segundo Pezzato et al. (2002).

Alevinos de acará-bandeira (Pterophyllum scalare) com peso vivo de 0,44 $\pm 0,05 \mathrm{~g}$ foram distribuídos em 16 aquários com capacidade para $25 \mathrm{~L}$, dotados de sistema de filtragem e aeração, com temperatura controlada por meio de termostato e aquecedor $\left(26 \pm 0,5^{\circ} \mathrm{C}\right)$, em densidade de 6 peixes/aquário. Os peixes foram alimentados à vontade, quatro vezes ao dia (às $8,11,14$ e 17h), durante 60 dias.

No preparo das rações, os ingredientes foram finamente moídos, misturados manualmente, umedecidos com água $\left(50 \pm 5^{\circ} \mathrm{C}\right)$ e peletizados. As rações foram secas em estufa de ventilação forçada durante 24 horas a $55 \pm 5^{\circ} \mathrm{C}$, sendo trituradas e peneiradas para obtenção de grânulos adequados ao tamanho dos peixes, conforme seu desenvolvimento no decorrer do experimento.

A cada sete dias, os aquários foram sifonados para a retirada de fezes acumuladas no fundo. Ao final do período
Tabela 1 - Composição percentual das rações experimentais Table 1 - Ingredient composition of the experimental diets

\begin{tabular}{|c|c|c|c|c|}
\hline \multirow[t]{2}{*}{$\begin{array}{l}\text { Ingrediente } \\
\text { Ingredient }\end{array}$} & \multicolumn{4}{|c|}{$\begin{array}{c}\text { Nível de PB (\%) } \\
\text { CP level }(\%)\end{array}$} \\
\hline & 34 & 38 & 42 & 46 \\
\hline Farinha de peixe & 15,00 & 15,00 & 15,00 & 15,00 \\
\hline $\begin{array}{l}\text { Fish meal } \\
\text { Farelo de soja } \\
\text { Soybean meal }\end{array}$ & 35,40 & 39,37 & 41,00 & 43,00 \\
\hline $\begin{array}{l}\text { Farelo de glúten de milho } \\
\text { Corn gluten meal }\end{array}$ & 10,00 & 15,00 & 21,50 & 27,68 \\
\hline Fubá de milho & 18,00 & 10,50 & 8,71 & - \\
\hline $\begin{array}{l}\text { Corn } \\
\text { Farelo de trigo } \\
\text { Wheat middlings }\end{array}$ & 11,00 & 10,00 & 7,50 & 7,50 \\
\hline $\begin{array}{l}\text { Amido de milho } \\
\text { Corn starch }\end{array}$ & 5,06 & 4,54 & 1,00 & 2,00 \\
\hline Óleo de soja & 2,36 & 2,50 & 2,27 & 1,80 \\
\hline $\begin{array}{l}\text { Soybean oil } \\
\text { Fosfato bicálcico } \\
\text { Dicalcium phosphate }\end{array}$ & 2,27 & 2,25 & 2,25 & 2,25 \\
\hline $\begin{array}{l}\text { DL-metionina } \\
\text { DL-methionine }\end{array}$ & 0,14 & 0,07 & - & - \\
\hline Sal comum & 0,25 & 0,25 & 0,25 & 0,25 \\
\hline $\begin{array}{l}\text { Salt } \\
\text { Suplemento vitamínico } \\
\text { e mineral }{ }^{1}\end{array}$ & 0,50 & 0,50 & 0,50 & 0,50 \\
\hline $\begin{array}{l}\text { Vitamin and mineral premix } \\
\text { Antioxidante } \mathrm{BHT}^{2} \\
\text { Antioxidant }(B H T)^{2}\end{array}$ & 0,02 & 0,02 & 0,02 & 0,02 \\
\hline $\begin{array}{l}1 \text { Níveis de garantia por quilo } \\
\text { product): vit. A, } 1.200 .000 U 1 \\
\text { K3, } 2.400 \mathrm{mg} ; \text { vit. B1, } 4.80 \\
\text { vit. B12, } 4.800 \mathrm{mg} ; \text { ác. fóli } \\
\text { (calcium pantothenate), } 12.000 \\
\text { colina (choline), } 65.000 \mathrm{mg} ; \mathrm{n} \\
6.000 \mathrm{mg} ; \mathrm{Mn}, 4.000 \mathrm{mg} ; \mathrm{Z} \\
2 \text { Butil hidroxi tolueno (Butil hi }\end{array}$ & $\begin{array}{l}\text { ama do } \\
\text { it. } \mathrm{D}_{3}, 2 \\
\mathrm{mg} ; \text { vit. } \\
\text { ( folic acic } \\
\text { g; vit. C, } \\
\text { cina(niac } \\
6.000 \mathrm{~m} \\
\text { oxi toluen }\end{array}$ & $\begin{array}{l}\text { uto (Gu } \\
00 \mathrm{Ul} ; \\
4.800 \\
200 \mathrm{mg} \\
000 \mathrm{mg} \\
24.000 \\
20 \mathrm{mg}\end{array}$ & $\begin{array}{l}\text { ylevels } \\
\mathrm{E}, 12.0 \\
\text { vit. B6, } \\
\text { totena } \\
\text { tina (bi } \\
=\mathrm{e}, 10.0 \\
2 \mathrm{mg} \text {; }\end{array}$ & $\begin{array}{l}\text { ilogram of } \\
\mathrm{mg} \text {; vit. } \\
000 \mathrm{mg} \text {; } \\
\text { le cálcio } \\
\text {, } 48 \mathrm{mg} ; \\
\mathrm{mg} ; \mathrm{Cu} \text {, } \\
20 \mathrm{mg} \text {. }\end{array}$ \\
\hline
\end{tabular}

Tabela 2 - Composição química das rações experimentais Table 2 - Chemical composition of the experimental diets

Composição química (valores calculados) Chemical composition (calculated values)

\begin{tabular}{|c|c|c|c|c|}
\hline $\begin{array}{l}\text { Energia } \\
\text { digestível }(\mathrm{kcal} / \mathrm{kg})^{1}\end{array}$ & $3.182,72$ & $3.201,56$ & $3.236,84$ & $3.214,29$ \\
\hline \multicolumn{5}{|l|}{ Digestible energy $(\mathrm{kcal} / \mathrm{kg})$} \\
\hline Proteína bruta (\%) & 34,04 & 38,06 & 42,16 & 46,05 \\
\hline \multicolumn{5}{|l|}{ Crude protein (\%) } \\
\hline $\begin{array}{l}\text { Proteína } \\
\text { digestível }(\%)^{1}\end{array}$ & 30,30 & 34,12 & 38,04 & 41,77 \\
\hline \multicolumn{5}{|l|}{ Digestible protein (\%) } \\
\hline $\begin{array}{l}\text { Extrato etéreo } \\
\text { total }(\%)\end{array}$ & 5,07 & 5,16 & 5,06 & 4,55 \\
\hline \multicolumn{5}{|l|}{ Ether extract (\%) } \\
\hline Fibra bruta $(\%)$ & 3,59 & 3,64 & 3,55 & 3,56 \\
\hline \multicolumn{5}{|l|}{ Crude fiber (\%) } \\
\hline Metionina (\%) & 0,60 & 0,60 & 0,62 & 0,70 \\
\hline \multicolumn{5}{|l|}{ Methionine (\%) } \\
\hline \multicolumn{5}{|l|}{ Calcium $(\%)$} \\
\hline Fósforo disponível $(\%)^{2}$ & )$^{2} \quad 0,70$ & 0,70 & 0,70 & 0,70 \\
\hline \multicolumn{5}{|c|}{ Available phosphorus (\%) } \\
\hline
\end{tabular}

1 Valores calculados com base nos coeficientes de digestibilidade para tilápia-do-nilo (Pezzato et al., 2002) [Calculated values based on digestibility coefficients for Nile tilapia (Pezzato et al., (2002)].

2 Valores calculados para tilápia do Nilo (Miranda et al., 2000) [Calculated values for Nile tilapia (Miranda et al., (2000)]. 
experimental, os peixes foram pesados em balança de precisão com resolução de $0,01 \mathrm{~g}$.

Ao final do experimento, foram avaliados os seguintes parâmetros de desempenho produtivo: peso final (PF), ganho de peso (GP), consumo de ração (CR), conversão alimentar (CA), taxa de crescimento específico (TCE) e taxa de eficiência protéica (TEP). O cálculo da TCE foi realizado utilizando-se a fórmula abaixo:

$$
\operatorname{TCE}\left(\% \mathrm{dia}^{-1}\right)=\left(\frac{\ln W_{f}-\ln W_{i}}{t}\right) 100
$$

em que: $\mathrm{W}_{\mathrm{i}}=$ peso médio inicial $(\mathrm{g}) ; \mathrm{W}_{\mathrm{f}}=$ peso médio final $(\mathrm{g}) ; \mathrm{t}=$ tempo de experimento (dias).

A TEP foi calculada utilizando-se a seguinte fórmula:

$$
T E P=\frac{G P}{C R \times \% \text { PBdieta }} \times 100
$$

A comparação dos parâmetros de desempenho produtivo entre os tratamentos foi realizada por meio de análise de variância e, em caso de teste F significativo, foi realizado o teste Tukey.

\section{Resultados e Discussão}

Os resultados obtidos para os parâmetros de desempenho produtivo são descritos na Tabela 3 .

Não foram observadas diferenças significativas para os parâmetros de desempenho produtivo entre os tratamentos, exceto para a taxa de eficiência protéica (TEP). Os peixes alimentados com a dieta contendo $46 \%$ PB apresentaram TEP significativamente $(\mathrm{P}<0,01)$ menor queaqueles alimentados com as dietas com 34 e $38 \%$ de PB, enquanto aqueles que receberam a dieta com $42 \%$ de PB não diferiram dos demais. Resultados similares foram observados para Ctenopharyngdeon idella (Dabrowski, 1977), Tilapia mossambica (Jauncey, 1982), Zacco barbata (Shyong et al., 1998) e Oreochromis niloticus (Abdelghany, 2000). Entretanto, Ribeiro (2005), utilizando dietas com 26, 28, 30 e 32\% de PB para alevinos de acarábandeira, não observou efeito sobre a TEP.

As taxas de crescimento específico (TCE) observadas foram equivalentes às obtidas por Rodrigues (2004), demonstrando boa eficiência de retenção de nutrientes por essa espécie. Luna-Figueroa (2003), comparando o desempenho produtivo de acarás-bandeira alimentados com alimentos vivos (Daphnia e larvas de mosquito) e três rações comerciais para ciclídeos, obteve TCE ainda maiores $(4,19$ a $6,29 \% / d i a)$, provavelmente por ter utilizado peixes menores (peso inicial $=0,06 \mathrm{~g}$ ).

Maehana et al. (2004) avaliaram as exigências de proteína para o acará-disco (Symphysodon spp), uma espécie de
Tabela 3 - Valores médios de peso final, ganho de peso, consumo de ração, conversão alimentar, taxa de crescimento específico (TCE) e taxa de eficiência protéica (TEP) de alevinos de acará-bandeira alimentados com rações contendo diferentes níveis de PB

Table 3 - Mean values of final weight, weight gain, feed intake, feed:gain ratio, specific growth rate (SGR) and protein efficiency ratio (PER) of freshwater angelfish fry fed diets with different $C P$ levels

\begin{tabular}{lcccc}
\hline & \multicolumn{4}{c}{$\begin{array}{c}\text { Nível de PB (\%) } \\
\text { CP level (\%) }\end{array}$} \\
\cline { 2 - 5 } & 34 & 38 & 42 & 46 \\
\hline $\begin{array}{l}\text { Peso final (g) } \\
\text { Final weight (g) }\end{array}$ & $1,84 \pm 0,25$ & $2,24 \pm 0,33$ & $1,96 \pm 0,24$ & $1,96 \pm 0,45$ \\
$\begin{array}{l}\text { Ganho de } \\
\text { peso (g) }\end{array}$ & $1,39 \pm 0,27$ & $1,78 \pm 0,26$ & $1,53 \pm 0,22$ & $1,53 \pm 0,40$ \\
$\begin{array}{l}\text { Weight gain (g) } \\
\text { Consumo de } \\
\text { ração (g) } \\
\text { Feed intake (g) }\end{array}$ & $3,39 \pm 0,40$ & $3,69 \pm 0,45$ & $3,37 \pm 0,38$ & $3,83 \pm 0,61$ \\
$\begin{array}{l}\text { Conversão } \\
\text { alimentar }\end{array}$ & $2,47 \pm 0,25$ & $2,09 \pm 0,26$ & $2,22 \pm 0,16$ & $2,58 \pm 0,39$ \\
$\begin{array}{l}\text { Feed:gain ratio } \\
\text { TCE (\%/dia) }\end{array}$ & $2,31 \pm 0,35$ & $2,61 \pm 0,15$ & $2,48 \pm 0,16$ & $2,46 \pm 0,26$ \\
SGR (\%/day) \\
$\begin{array}{l}\text { TEP } \\
P E R\end{array}$ & $1,20 \pm 0,12 \mathrm{a}$ & $1,28 \pm 0,18 \mathrm{a}$ & $1,08 \pm 0,07 \mathrm{ab}$ & $0,86 \pm 0,14 \mathrm{~b}$ \\
\hline
\end{tabular}

Médias seguidas da mesma letra não diferem $(P>0,01)$ pelo teste Tukey. Means followed by the same letter do not differ $(P>0.01)$ by Tukey test.

hábito alimentar e ambiente natural semelhantes, da mesma família do acará-bandeira, e não observaram diferenças significativas para o ganho de peso nos alevinos alimentados com rações contendo 35, 40, 45 e 50\% de PB. Esses resultados são semelhantes aos observados neste experimento para o acará-bandeira e indicam que a exigência em proteína para alevinos dessas espécies deve ser igual ou inferior a 35\% de PB. Entretanto, Chong et al. (2000), utilizando rações com $35,40,45,50$ e $55 \%$ de PB, observaram que a exigência em proteína estimada para maximizar a TCE de alevinos de acará-disco é de 44,9 a 50,1\% de PB.

Resultados conflitantes sobre a exigência de proteína também têm sido observados para outras espécies de ciclídeos, como a tilápia-do-nilo (De Silva et al., 1989; El-Sayed \& Teshima, 1992; Abdelghany, 2000; Hayashi et al., 2002).

Prováveis causas para essas diferenças nos resultados podem ser atribuídas ao fornecimento inadequado das rações, tanto em quantidade como em freqüência, visto que a taxa de ingestão de alimentos é essencial na determinação da exigência de proteína para peixes (McGoogan \& Gatlin III, 1997; Arzel et al., 1998). A concentração de energia digestível da dieta, a composição de aminoácidos e a digestibilidade da proteína dos ingredientes utilizados também podem interferir na determinação das exigências de proteína dos peixes (Wilson, 1989). 
Os níveis de PB avaliados neste estudo não permitiram a obtenção da exigência nutricional para alevinos de acarábandeira, pois o menor nível deste nutriente na dieta (34\%) atendeu às necessidades protéicas da espécie. Ribeiro (2005), utilizando dietas com 26, 28, 30 e 32\% de PB para alevinos da mesma espécie, obteve os melhores resultados com a ração contendo $32 \%$ de $\mathrm{PB}$, o que indica que a exigência de $\mathrm{PB}$ para alevinos de acará-bandeira é de 32 a $34 \%$ de PB.

Os resultados deste estudo permitirão formular rações mais adequadas à espécie, promovendo o crescimento rápido e eficiente e contribuindo para a redução dos custos de criação e da eutrofização da água de cultivo e dos efluentes.

\section{Conclusões}

Dietas contendo $34 \%$ de PB atendem às exigências nutricionais em proteína de alevinos de acará-bandeira.

\section{Agradecimento}

Ao Conselho Nacional de Pesquisa (CNPq), pela concessão de bolsa de iniciação científica ao terceiro autor, e à União de Produtores de Peixes Ornamentais da Região de Muriaé, MG (UNIPEIXE), que, por meio da zootecnista Verônica Cruz, cedeu os peixes utilizados neste estudo.

\section{Literatura Citada}

ABDELGHANY, A.E. Optimum dietary protein requirements for Oreochromis niloticus L. fry, using formulated semipurified diets. In: TILAPIA AQUACULTURE INTERNATIONAL SYMPOSIUM ON TILAPIA AQUACUlTURE, 5., 2000, Rio de Janeiro. Proceedings... Rio de Janeiro: 2000. v.1, p.101-108.

ARZEL, J.; METAILLER, R.; LE GALL, P. et al. Relationship between ration size and dietary protein level varying at the expense of carbohydrate and lipid in triploid brown trout fry, Salmo trutta. Aquaculture, v.162, p.259-268, 1998.

CHAPMAN, F.A.; FITZ-COY, S.A.; THUNBERG, E.M. et al. United States of America trade in ornamental fish. Journal of the World Aquaculture Society, v.28, n.1, p.1-10, 1997.

CHONG, A.S.C.; HASHIM, R.; ALI, A.B. Dietary protein requirements for discus (Symphysodon spp.). Aquaculture Nutrition, v.6, p.275-278, 2000.

DABROWSKY, K. Protein requirements of grass carp fry (Ctenopharyngdeon idella Val.). Aquaculture, v.12, p.63-73, 1977.

DE SILVA, S.S.; GUNASEKERA, R.M.; ATAPATTU, D. The dietary protein requirements of young tilapia and an evaluation of the least cost dietary protein levels. Aquaculture, v.80, n.3-4, p.271-284, 1989.

EL-SAYED, A.M.; TESHIMA, S. Protein and energy requirements of Nile tilapia, Oreochromis niloticus, fry. Aquaculture, v.103, p.55-63, 1992.

HAYASHI, C.; BOSCOLO, W.R.; SOARES, C.M. et al. Exigência de proteína para larvas de tilápia do Nilo (Oreochromis niloticus), durante a reversão sexual. Revista Brasileira de Zootecnia, v.31, n.2, p.823-828, 2002.

JAUNCEY, K. The effect of varying dietary protein level on growth, food conversion, protein utilization and body composition of juvenile T. mossambica. Aquaculture, v.27, p.43-54, 1982.

LIMA, A.O.; BERNARDINO, G.; PROENÇA, C.E.M. Agronegócio de peixes ornamentais no Brasil e no mundo. Panorama da Aqüicultura, v.11, n.65, p.14-24, 2001.

LUNA-FIGUEROA, J.Pterophyllum scalare (Pisces: Cichlidae): Influencia de alimento vivo em la reproducción y el crecimiento. Disponível em: 〈http://www.civa2003.org> Acesso em: 12/08/05

MAEHANA, K.R.; RIBEIRO, R.P.; FURLAN, A.C. et al. Determinação da exigência em proteína para alevinos de acará disco (Symphysodon spp.). In: CONGRESSO DA SOCIEDADE BRASILEIRA DE AQÜICULTURA E BIOLOGIA AQUÁTICA, 1., 2004, Vitória. Anais... Vitória: Sociedade Brasileira de Aqüicultura, 2004. p.407.

MCGOOGAN, B.B.; GATLIN III, D.M. Metabolic requirements of red drum, Sciaenops ocellatus, for protein and energy based on weight gain and body composition.Journal Nutrition, v.128, p.123-129, 1997.

MIRANDA, E.C.; PEZZATO, A.C.; PEZZATO, L.E. et al. Disponibilidade aparente de fósforo em ingredientes pela tilápia do Nilo (Oreochromis niloticus). Acta Scientiarium, v.22, n.3, p.669-675, 2000.

NATIONAL RESEARCH COUNCIL - NRC. Nutrient requirements of fish. Washington, D.C.: National Academy Press, 1993. $114 \mathrm{p}$.

PEZZATO, L.E.; MIRANDA, E.C. M.; BARROS, M.M. et al. Digestibilidade aparente de ingredientes pela tilápia do Nilo (Oreochromis niloticus). Revista Brasileira de Zootecnia v.31, n.4, p.1595-1604, 2002.

PEZZATO, L.E.; SCORVO FILHO, J.D. Situação atual da aqüicultura na região sudeste. In: VALENTI, W.C. (Ed.) Aqüicultura no Brasil: bases para um desenvolvimento sustentável. Brasília: CNPq/Ministério da Ciência e Tecnologia, 2000. p.303-322.

RIBEIRO, F.A.S. Desempenho do acará bandeira (Pterophyllum scalare) com diferentes níveis de proteína bruta. Jaboticabal: Universidade Estadual Paulista, 2005. 27p. Monografia (Graduação em Zootecnia) - Universidade Estadual Paulista, 2005

RODRIGUES, L.A. Influência do processamento da dieta no desempenho produtivo do acará bandeira (Pterophyllum scalare). Jaboticabal: Universidade Estadual Paulista, 2004 30p. Dissertação (Mestrado em Aqüicultura) - Universidade Estadual Paulista, 2004.

ROSTAGNO, H.S.; ALBINO, L.F.T.; DONZELE, J.L. et al.Tabelas brasileiras para aves e suínos: composição de alimentos e exigências nutricionais. 1.ed. Viçosa, MG: Universidade Federal de Viçosa, 2000. 141p.

SALES, J.; JANSSENS, G.P.J. Nutrient requirements of ornamental fish. Aquatic Living Resources, v.16, n.6, p.533-540, 2003.

SHYONG, W.J.; HUANG, C.H.; CHEN, H.C. Effects of dietary protein concentration on growth and muscle composition of juvenile Zacco barbata. Aquaculture, v.167, p.35-42, 1998.

WILSON, R.P. Amino acids and protein. In: HALVER, J.E. (Ed.) Fish nutrition. 2.ed. New York: Academic Press, 1989 p. 111-151.

WILSON, R.P., HALVER, J.E. Protein and amino acid requirements of fishes. Annual Review of Nutrition, v.6, p.225-244, 1986 